\title{
IDENTIFICATION OF THE SPORTS PREDISPOSITION AS A SOCIAL RISK MANAGEMENT ELEMENT
}

\author{
Elena Fefilova ${ }^{1}$ \\ Natalia Pazdnikova ${ }^{2}$ \\ Yuliya Karpovich ${ }^{3}$
}

DOI: https://doi.org/10.31410/ITEMA.2019.61

\begin{abstract}
The relevance of activities on sports selection and sports orientation of children, including in order to assess health risks, is substantiated. A method for identifying a sports predisposition based on sports selection and orientation methods has been formed, and testing has been conducted. As part of the study, a group of participants was identified for which recommendations were made to limit the use of sports due to health risks. A financial risk assessment was carried out. The suggestions are formulated for using the methodology for identifying sports predisposition as a risk management tool.

Aim of the study is the health risk assessment based on the methodology of sports selection and orientation.

Materials and methods. The methods of theoretical analysis and generalization, the bibliographic method of searching and studying scientific information, and system analysis are used.
\end{abstract}

Keywords: Sports Selection, Sports Orientation, Health Risks, Risk Management

\section{INTRODUCTION}

A new stage in the development of the Russian Federation is marked by the large-scale implementation of national projects as an instrument designed to ensure a qualitative change in the standard of living of the population in all areas. One of the key indicators of the national project „Demography" involves an increase in the proportion of citizens who are systematically involved in physical education and sports, up to 55\%. This goal, in addition to popularizing the aspects of a healthy lifestyle, involves ensuring a competitive sports infrastructure and the development of the institution of sports training, including institutions of the municipal, regional and federal levels that operate within the framework of the budget for results-based budgeting and provide state social services. Note that in the framework of federal law, the criterion for distinguishing between the categories of "sports" and "physical education" is the implementation of competitive activity.

In accordance with the Budget Code of the Russian Federation, such institutions operate within the framework of the state (municipal) assignment mechanism and provide sports training services in Olympic, non-Olympic sports, sports for people with disabilities in the context of the stages of initial preparation, training, the stage of improvement of sportsmanship, stage of higher sportsmanship, while financing is carried out according to the normative per capita principle per one Nima, provided the job. To determine the quality of the service, it is assumed to use an indicator that reflects the sustained interest of those involved in the sport (the share of students enrolled in the next stage), and the athlete's compliance with the federal standards. Note that the factors of conducting competitive activity and its effectiveness, which are fundamental for the formalization of sports training, are ignored.

\footnotetext{
Perm National Research Polytechnic University, Komsomolsky Avenue, 29, 614990 Perm, Russia Perm National Research Polytechnic University, Komsomolsky Avenue, 29, 614990 Perm, Russia Perm National Research Polytechnic University, Komsomolsky Avenue, 29, 614990 Perm, Russia
} 
Every year, about 30-40 percent of people undergoing sports training are screened out during the transition between stages, including for health reasons and due to non-compliance with control standards. In addition, because of the initially non-optimal choice of sport, a young athlete, having spent years training, reaches the limit of his physical, anthropometric, psychological capabilities, which leads to stagnation or deterioration of sports results.

The issues of planning the volumetric indicators of state sports training services (the number of people involved in the preparation stage) are determined by the following factors: limited budget funding (planning is carried out "from the reverse"), the level of provision of the territory with sports organizations, and material and technical equipment. At the same time, considering the institute of sports of the highest achievements, the question of forecasting optimal for ensuring the formation of a competitive sports reserve, the number of participants remains unresolved (Bakulev S.E. et al., 2017; Aleshin I.N., 2018). At the same time, domestic researchers determine the low level of efficiency of forecasting competitive activity by insufficient awareness and use of information about the sports makings of future athletes (Zebzeev V. V., 2015).

In addition, in the framework of modern scientific research, a conclusion has been drawn about possible negative consequences for the physical and psychological health of athletes, especially significant in cases of applying inappropriate loads to the body's capabilities applied at all stages of sports training (5-8). So, according to research, the initial number of visits to medical institutions of young athletes is 3.7 times higher than the value of a similar indicator among children who are not involved in sports (Avdeeva T. G., 2009). At the moment, there is an extremely high level of sports improvement and competition, which leads to an increase in the intensity of the training process, an increase in loads and aggravates the influence of risk factors on the health of young athletes.

Thus, the relevance of enhancing the activities of sports selection and orientation of children, the development of technologies for identifying sports orientation is obvious.

\section{METHODOLOGY}

In the framework of studying the processes for identifying a sports orientation, the establishment of a conceptual apparatus is of particular importance: sports selection is a system of organizational and methodological measures, including pedagogical, psychological, sociological and biomedical research methods, on the basis of which the abilities of children, adolescents and youths for specialization are identified in a particular sport or group of sports, while sports orientation reflects the opposite process - definition of sport or specialization areas, the most appropriate level of abilities, inclinations and interests of the child (Volkov V.M., Filin V.P., 1983). In the first case, the goal is to identify the most gifted children for sports, in the second - the determination of the sports path for both young athletes and children involved in physical education. At the same time, a number of authors consider orientation as one of the stages of selection, which is an activity to determine a narrow sports specialization in a particular sport (Volkov V.M. et al., 1983; Melikhova T.M., 2006).

It should be noted that activities within the framework of sports orientation require the use of more complex technology for its implementation, analysis of an extensive methodological and methodological base, as well as tools for processing and interpreting test results. At the same time, domestic researchers highlight the problem of the lack of unified methodological 
approaches to assessing abilities and justify the need to review, systematize and update existing methods (Shvarts V.B., Khrushchev S.V., 1984), in addition, the need for the use of information technologies in testing is substantiated.

Basically, the following aspects of sports orientation and selection are distinguished: pedagogical (assessment of motor function, motor skills, coordination abilities, etc.), psychological (determination of personality characteristics, structure of psychological activity, identification of interest in activities), biomedical (assessment of health, morphological and functional characteristics of the body, level of adaptation to physical activity, etc.), sociological (study of motivation, the influence of family, sport, team) (Sergienko L.P., 2013).

\section{DISCUSSION}

As part of the study, we have developed a methodology for identifying a sports orientation and assessing health risks, based on a comparison of test results with standard indicators established for the corresponding gender and age group by domestic researchers. The criteria used in the diagnostic process are shown in table 1 .

Table 1 - Criteria for sports orientation

\begin{tabular}{|l|l|l|}
\hline Criteria group & Complex factors & Tests and indicators \\
\hline \multirow{5}{*}{$\begin{array}{l}\text { Pedagogical (assessment } \\
\text { of physical qualities) }\end{array}$} & Speed abilities & 30 m running \\
\cline { 2 - 3 } & Muscular strength & $\begin{array}{l}\text { Flexion-extension of the arms in an } \\
\text { emphasis lying }\end{array}$ \\
\cline { 2 - 3 } & Vestibular resistance & Roymberg test \\
\cline { 2 - 3 } & Stamina & Planck, torso lift \\
\cline { 2 - 3 } & Flexibility & $\begin{array}{l}\text { Tilt forward from a standing / lying } \\
\text { position }\end{array}$ \\
\hline \multirow{5}{*}{$\begin{array}{l}\text { Biomedical } \\
\text { (Anthropometric) }\end{array}$} & Coordination Ability & Coordination Ability \\
\hline & Speed and Power Ability & Long Jump \\
\hline \multirow{5}{*}{ Psychological } & Level of Physical Development & Body Mass Index (WHO) \\
\cline { 2 - 3 } & Body Proportionality & Proportionality Index \\
\hline & Persistence of Attention & Schulte Tables \\
\cline { 2 - 3 } & Reaction rate & Hand-eye reaction \\
\cline { 2 - 3 } & Individual personality characteristics & Individual typological questionnaire \\
\cline { 2 - 3 } & Type of nervous system & tapping test \\
\cline { 2 - 3 } & Type of temperament & $\begin{array}{l}\text { Testing to determine the type of } \\
\text { temperament }\end{array}$ \\
\cline { 2 - 3 } & Formation of motives for activity & $\begin{array}{l}\text { Test for determining leading } \\
\text { activities }\end{array}$ \\
\hline
\end{tabular}

In order to ensure the coverage of various sports in assessing predisposition, our methodology in terms of assessing physical qualities contains tests and indicators that, on the one hand, are accessible and feasible for the subject, on the other hand, correspond to those complex factors that reflect physical fitness requirements, presented by various sports (N.G. Ongienko, I.S. Voropai, L.P. Sergienko, P.V. Ostashev, etc.), in accordance with relevant approaches, the coefficient of significance of criteria for a sport (in accordance with the accepted classifications of sports, Olympic and non-Olympic sports are distinguished, which in turn are divided into winter and summer sports, as well as by groups that characterize the features of the activities carried out in the framework of training for these types: cyclic, martial arts, applied, difficult coordination, shooting, speed-strength, technical), determined by factors of the age of the beginning of reception and the degree of influence of the studied abilities, qualities, inclinations on sports s results. 
Evaluation within each criterion involves determining the individual level of motor abilities based on the correlation of an individual test result with normative indicators, the scale including the allocation of unsatisfactory results and hazard markers, which are the basis for generating information about the presence of health risk.

The integral assessment of physical qualities (AFQ) for the jth sport (group of species) is calculated by the formula:

$$
A F Q_{j}=F Q_{1} * s_{1}+F Q_{2} * s_{2}+\ldots+F Q_{i} * s_{i}
$$

where: $F Q$ - coefficient of the individual level of motor abilities according to the i-th criterion;

$\mathrm{s}$ - coefficient of significance of the i-th criterion.

A feature of anthropometric criteria is the need to consider each of them in relation to the specific requirements of the sport (group of sports). When evaluating the obtained value is compared with a given model characteristic, which is optimal for a specific group of sports.

Psychological criteria determine the need to use a significant number of instrumental methods (G. Aizenk, O.E. Yashchin, A.A. Krylov, S.A. Manichev, E.P. Ilyin, etc.), each of which has its own calculation algorithm and scale results. In order to unify in accordance with the significance of the test results for a sport, these parameters are reduced to a 5-point system ( $0-2$ points -- health risk, 3-4 -- satisfactory, 5 -maximum level of compliance).

Comprehensive diagnostics of a sports orientation is a choice from an array of ratings for each of the studied sports (groups) that are most relevant (in accordance with the rating scale) to the athlete's individual profile, the level of his abilities, qualities and inclinations. A separate group is formed by persons with respect to whom a health risk is identified during sports.

It should be noted that the technology for identifying sports orientation based on the presented methodology involves the use of an information system that allows you to collect, store, process, analyze large amounts of data.

\section{RESULTS}

As part of the testing of the methodology, testing was organized for participants in the Perm International Marathon (September 2019): a sample of children involved in athletics (at the sports and fitness, primary or sports and fitness stage of sports training) was formed, aged 6 to 15 years.

The organizational and technical parameters of the testing made it necessary to include short, easy to implement, and, at the same time, significant tests in the process of sports selection in the diagnostic process of sports involvement (test to determine leading activity (psychological criterion), measurements by anthropometric criteria, rapid assessment - power, coordination abilities). Interpretation of the results provides for the development of recommendations for practicing complex coordination sports, which assess the complexity and beauty of the movements performed (for example, ski biathlon) - the first group; cyclic sports, requiring a primary manifestation of endurance, with a significant duration of competitive exercises (athletics, cycling, etc.) - the second group; recommendations of daily physical activity in accordance with the recommendations of the All-Russian Health Organization (health risks identified) - the third group. 
Table 2. - Distribution of test results (gender and age composition)

\begin{tabular}{|l|c|c|c|}
\hline Age and gender category & Group 1 & Group 2 & Group 3 \\
\hline Girls (6-10 years old) & $32,20 \%$ & $40,68 \%$ & $27,12 \%$ \\
\hline Boys (6-10 years old) & $17,81 \%$ & $60,27 \%$ & $21,92 \%$ \\
\hline Girls (11-13 years old) & $29,63 \%$ & $44,44 \%$ & $25,93 \%$ \\
\hline Boys (11-13 years old) & $24,00 \%$ & $85,19 \%$ & $7,40 \%$ \\
\hline Girls (14-15 years old) & $40,00 \%$ & $60,00 \%$ & - \\
\hline Boys (14-15 years old) & $20,00 \%$ & $80,00 \%$ & - \\
\hline Average meaning & $27,27 \%$ & $56,90 \%$ & $15,83 \%$ \\
\hline
\end{tabular}

The results of the study showed a rather high level of predisposition to cyclic sports - about $60 \%$ of the total number of participants.

Almost a third of young athletes showed indicators that form a positive prognosis in the framework of complex coordination sports.

Within the age group of 14-15 years, recommendations for physical activity were not formed due to the presence of health risks (group 3), which demonstrates the effectiveness of the implementation of sports selection and orientation at the training stage.

At the same time, on average, in relation to $16 \%$ of the participants recommendations were made to limit sports, which are caused not only by unfavorable forecasts of competitive activity, but also by health risks. More than half of the children in this group are between the ages of 6 and 10 years and the availability of information about sports predisposition, taking into account the average age of admission to the initial stage of sports training (9-10 years), provides parents and teachers with the opportunity to form a health-saving path for the development of the child.

In the framework of the study, in addition to the individual (private) nature and social orientation of the risks to the health of children involved in sports, it is possible to single out financial risks of a general nature, the subject of which is the institution of public administration. An assessment of such risks can be made on the basis of information that $21.9 \%$ of those involved in the initial stage of sports training (11-13 years old) have abilities, qualities and inconsistencies that do not correspond to sports, which directly affects the results of fulfilling control standards and the implementation of competitive activity and determines the inefficient use of budget funds for the training of such an athlete. For example, for the consolidated budget of the Perm Territory, the assessment of this risk is 33.5 million rubles (based on the average value of standard costs for the provision of sports training services at the initial stage - 52.4 thousand rubles per year for the student and the number of students at the stage initial training).

The health risks under study also determine the frequency and nature of visits to medical institutions for children whose physical indicators do not correspond to the level of training load in the framework of the chosen sport. The object of financial risk in this situation is the health authorities and compulsory health insurance funds, an assessment of such a risk at the Perm Territory is 7 million rubles. per year (based on the funding standard of 15.3 thousand rubles per person per year from all sources and the number of people involved).

The total financial risk assessment at the level of the Russian Federation is 9.1 billion rubles. (including 1.92 billion rubles for the budget of compulsory health insurance funds). 


\section{CONCLUSION}

As part of the study, the methods of sports selection and orientation were used to manage social risks (children's health). Diagnostic mechanisms for sports predisposition provide increased competitiveness of sports activities, sustained interest in sports and the effectiveness of the provision of public sports training services by minimizing the cost of preparing a sports reserve. The application of the methodology for identifying a sports predisposition as a risk management tool will make it possible to mitigate the health risks of students by identifying the level of compliance of their abilities and inclinations with the requirements and potential loads.

\section{REFERENCES}

Aleshin I.N., Slinkina N.E., Samoilova E.L. (2018) The uncertainty and nonlinearity in sports training course, manifestations and implementation. Problemy sovremennogo pedagogicheskogo obrazovaniya, no.58-3, pp.33-40.

Avdeeva T. G. (2009) Introduction in children's sports medicine. Moscow: GEOTAR-Media, $176 \mathrm{p}$.

Bakulev S.E. (2009) Improvement of the success forecasting effectiveness of combat sports athletes taking into account genetic bases of patrimonial, interspecific and intraspecific orientation. Uchenye zapiski universiteta Lesgafta, no.11 (57), pp. 35-39.

Bakulev S.E., Dveirina O.A. (2017). Determination of number of athletes for prospect, nearest and current reserve as a way to manage preparation of sports national teams of the Russian Federation. Uchenye zapiski universiteta Lesgafta, no.4 (146), pp. 17-26.

Gavrilova E.A., Larintseva O.S. (2018) Risk factors for sudden cardiac death in athletes at various stages of sports training according to a cardiac examination. Sportivnaya meditsina: nauka i praktika, 2018, no.2, pp.33-37.

Makarov L.M. (2017). Sport and sudden death in children. Rossiiskii vestnik perinatologii $i$ pediatrii, no.1, pp.40-46.

Melikhova T.M. (2006) Implementation of principles and technologies of sports selection and orientation. Uchenye zapiski universiteta Lesgafta, 2006, no.22, pp. 37-41.

P. Taylor, L. Davies, P. Wells, J. Gilbertson, W. Tayleur. (2019) A review of the Social Impacts of Culture and Sport. Available at: https://assets.publishing.service.gov.uk/government/ uploads/system/uploads/attachment_data/file/416279/A_review_of_the_Social_Impacts_ of_Culture_and_Sport.pdf (02.10.2019).

Sergienko L.P. (2013) Sports selection: theory and practice. Moscow: Sovetskii sport, 1048 p.

Shvarts V. B., Khrushchev S. V. (1984) Biomedical aspects of sports orientation and selection. Moscow: Fizkul'tura i sport, 1984, 151 p.

Volkov V.M., Filin V.P. (1983) Sports selection. Moscow: Fizkul'tura i sport, 1983, 176 p.

Zebzeev V. V. (2015). Comparative analysis of the morphological features of Nordic combined skiers representing the different types of competitive qualification. Uchenye zapiski universiteta Lesgafta, no.5 (123), pp. 75-79. 